\title{
The Thinking of the Strategic Positioning of Qinhuangdao Marine Economic Development
}

\author{
Yin Fan \\ Environmental Management College of China \\ Qinhuangdao, China \\ yinfan1015@163.com
}

\begin{abstract}
Ocean is the potential wealth of human society sustainable development in 21 st century, the development and utilization of marine resources is a new growth point of our national economy in the future. Under the deep analysis of the evolution process of Qinhuangdao ocean development path, the future marine economic development strategy of Qinhuangdao has been discussed.
\end{abstract}

Keywords-Marine Economy, Development Path, Strategic Positioning.

\section{INTRODUCTION}

Qinhuangdao is one of the first open coastal cities in China, is an important seaport of foreign trade in the North. However, over the years, the economic development of Qinhuangdao has stayed in the "economic downturn" of China's coastal zone. As the mainstay of Qinhuangdao coastal areas, Qinhuangdao is lack of driving force of the whole city's economic development, the marine economy development lags behind and fails to give full play to the advantages of the coastal area. With the coastline of 162.7 kilometers, sea area within $0 \sim 25$ meters deep contour of 2 , 629.4 square kilometers, the economic and social development of Qinhuangdao is established in the sea. The exploitation of ocean is a matter of life and death for the economic and social development of Qinhuangdao. It's necessary to analyze the evolution process of Qinhuangdao ocean development path, so as to location the strategic of Qinhuangdao ocean development accurately, and put it on a fast lane.

\section{THE EVOLUTION PATH OF QINHUANGDAO OCEAN EXPLOITATION}

\section{A. The Survival Stage of "Fishing, Harbor, Scenery" (Before 1987)}

The discovery of mutilated animal fossils and ashes in the karst cave of Wushan located in Lulong, Qinhuangdao, proved that humans have engaged in the acquisition, fishing and hunting activities here as early as in the ancient times. The so-called reflects environment every day, relying on ocean draft, the earliest ocean development is offshore fisheries as the entry and acting point. This usage is limited to "Profits of Fish and Salt, Benefits of Water transport" [1]. Marine fishery has always been the marine basic industry of Qinhuangdao, according to the CHINA CITY STATISTICAL YEARBOOK, in 1984, the output of aquatic products of Qinhuangdao came to 12.3 thousand tons. In the year 1987, the harbor has been built, and the Port of Authority has been set up, the transportation of coal has been the main business. The beautiful scenery is always stay in naturally state, including Xishan of Beidaihe, Shanhaiguan and so on.

\section{B. The Exploitative Stage of "Harbor, Fishing, Tour"'(1987 2000)}

Before the reform and opening, harbor industry in Qinhuangdao is few and foreign capital project is none. After the coastal port cities opening-up, the local authority is expanded and more favor are given to foreign investors to attract investment. From then on, Qinhuangdao run to the fast track of development and draws a large number of projects, including foreign ones. In the early $1980 \mathrm{~s}$, Qinhuangdao into the exploitative stage of "harbor, fishing, tour".

\section{1) Preliminary Usage of the Rich Harbour Shoreline Resources}

Qinhuangdao port is located in the middle of Bohai Bay, is the China's biggest coal port of shipment and one of the major ports along the coast of China. The Third Plenary Session of the eleventh CPC central committee pulled open the wave of reform and opening up. Qinhuangdao took this opportunity to seriously implement the "adjustment, reform and reorganization" and "open" policy, formulated the overall train of thought that "relying on the port and expand two lines, fully open", with large open to promote fast development and foreign economic has made great progress [2]. The actual amount of foreign capital up from 50 thousand dollars to 148 million from 1984 to 2000, the average annual growth of $46.8 \%$. The changing trend of Qinhuangdao port's cargo throughput is shown in figure 1 .

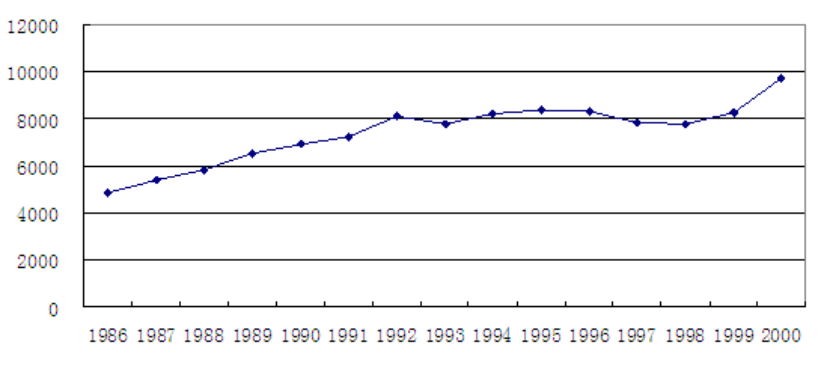

Fig 1. The Cargo throughput (Ten Thousand Tons) of Qinhuangdao Port 
2) The Advantages of Traditional Marine Fishery is Fading Out

As the update of the new fishing techniques and the marketing of seafood, the total catch of Aquatic products has been rapidly rise. In 2000, the output value of Qinhuangdao fishing industry reached 577 million yuan. Marine fishery industry started to transform and upgrade, the secondary industry led by aquatic product processing and the tertiary industry led by ocean recreational fishery has gradually replaced the primary industry. The production organizational form of marine fishery industry has been enriched and expanded (shown in Fig.2). But not for long, the number of fishing has sharply reduced, the kinds of fish declined to 30 from 63 by the survey in 1983, caused by over-fishing and ocean pollution ${ }^{[3]}$.

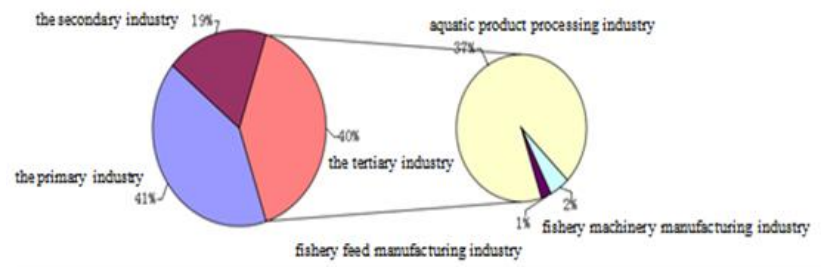

Fig 2. The Three Industries Structure Allocation of Qinhuangdao Marine Fshery in the year of 2000

3) Recovery and Rapid Development of Tourism

As early as in 1898, the Qing Government formally named Beidaihe as "the summer resort of the people". By 1984, the number of domestic and overseas tourists has reached more than 3.2 million. To develop coastal tourism and marine resources can extend industry chain and play a leading role. In the Economic and Technological and Society Development Strategy of Qinhuangdao in 2000 , the Municipal Party Committee and Municipal Government took the tourism as one of the local advantages, established the policy of "east west extension guide" to develop tourism, compiling the Plan of Qinhuangdao Tourism Development ${ }^{[4]}$. Then, the development of tourism has been rise to a strategic height. Qinhuangdao started to develop tourism resources gradually, perfect tourist facilities and built the tourism layout featuring the Great Wall culture and coastal.

\section{The Development Stage of "Tour, Harbor, Fishing" (After 2001)}

\section{1) Vigorously Develop the Coastal Tourism}

Since 2001, the marine economy industry structure of Qinhuangdao has been in the industry pattern of "three/two/one". During the Tenth Five-Year Plan, the ocean economy of Qinhuangdao is increasing at an annual rate of $16 \%$. In September 2009, the Municipal Party Committee and Municipal Government established the "Tourism Sitting up City" strategy, to speed up the adjustment of tourism industrial structure, transformation and upgrading of tourism products, the construction of tourism projects and increase the activeness of tourism market development and the level of tourist reception. By the end of 2010, a total of 47 tourist scenic spot all over the city, the amount of national A-class scenic areas is 27 . There are 65 star-rated hotels, including 7738 rooms and 15400 beds in all, at the forefront of the province. In recent years, the number of tourism tourists in Qinhuangdao has been on the rise, the tourism income has been increased year by year (shown in Figure 3). In 2013, the total of tourists up to 25.9 million and the tourism income reach 25.6 billion yuan.

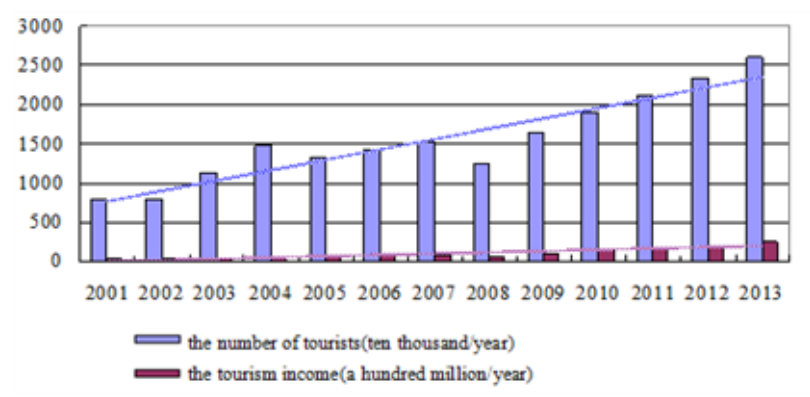

Fig 3. The Total Tourists and Tourism Income From 2001 to 2013 2) Accelerate Comprehensive Development of the Port

The strategy of "two ring opening drive", promoted the development of marine economy, particularly in marine transportation industry. After entering the period of "11th Five-Year Plan", Qinhuangdao has completed the "coal five period" , opened more than 3 container berths and international routes, built long distance pipeline transportation lines. That make throughput up to 257 million tons in 2010, increasing a rate of $52 \%$ from the 2005 , and the comprehensive energy consumption is $16 \%$ lower than it was in 2005. At present, the Qinhuangdao port has become the port of bulk cargo shipping and coal transshipment with the largest throughput in the world. While maintaining the pivotal status, Qinhuangdao port adjusts the layout of the coastline and changes into a multifunctional, modern, environmental and comprehensive international port.

3) Marine Fishery Transform to Ecological Fishery

Since 2001, the coastal counties like Shanhaiguan, Beidaihe, Funing, Changli, have begun to farm at sea in a large-scale, developed ecological fishery actively. Since 2002, more than 1700 fishing boats have been cut down. In accordance with the requirements of " ecology, health, circulation, intensive" , national level health ecological farming demonstration area of shallow sea raft scallops at scale of 30 thousand mu in Funing and provincial level farming demonstration area of scallops at scale of 50 thousand $\mathrm{mu}$ have been built, bring ecological and economic benefit remarkably. From 2000 to 2010 , Qinhuangdao successively invested 166 million yuan to the construction of marine ranching. Now the ocean pasture area has reached 55 thousand mu. The marine biological populations increased significantly, a variety of high value fishery resources gathered obviously, the bottom of the sea ecological environment improved significantly.

\section{THE STRATEGIC POSITIONING OF QINHUANGDAO OCEAN DEVELOPMENT}

\section{A. Create the National Marine Ecological Environmental Demonstration Area and the Optimal Coastal Livable Place}

Qinhuangdao sticks to the developmental request of coordinating sea and land, ecological priority, green evolution and harmony between production, life and ecology, designs the coastal line of production, life and ecology reasonably, develops ecological industry to reduce energy and resource, comprehensively promotes cleaner 
production, speeds up the development of circular economy and ecological economy, efforts to keep the excellent environment quality ${ }^{[5]}$. To strengthen the protection of the marine environment and speed the construct of ecosystem of the coastal zone. Qinhuangdao will be the marine ecological civilization demonstration city with developed marine economy, beautiful environment and the most optimal coastal livable city.

\section{B. Create the Biggest Seashore Leisure Base in the North and the international ecological tourism health resort}

Qinhuangdao makes full use of its unique tourism resources, seaside tourism and cultural advantages to build "coastal destination circle" surrounding Bohai and intensive industry zone of coastal ecological tourism. Especially depending on the Beidaihe's pleasant climate, the centralized superior resources actively, by the year 2015, Qinhuangdao makes his effort to build a coastal city of livable, business, tourism and the largest national famous historical and cultural city and tourist destination of sightseeing, leisure, vacation and summer, recuperate, enhancing popularity and attraction of Qinhuangdao. By 2020, Qinhuangdao becomes a first-class leisure resorts, ecological land, the highland of the Great Wall culture, longevity and healthy city in the word, owns to the brand image of "Great Wall coastal gallery, four seasons leisure paradise".

\section{Create New Logistics Center Led by International Comprehensive Port}

Making full use of regional advantage in the Bohai economic circle and adjacent to Shandong and Liaoning provinces with strong sea science and technology and developed marine economic, Qinhuangdao speed up to implement the plan of "move the west port to the east", perfect the construction of port, railway, highway and airport. Finally, high grade road system, powerful railway network and high density airline network have been built, a modern comprehensive transportation network of port, logistics and airport logistics have been created. Qinhuangdao takes the opportunity of cooperation with Dalian Commodity Exchange to develop coal related derivatives, put the varieties of coal price index futures into market and build the mid-long-term market and coal physical delivery system etc. Qinhuangdao will become international logistics node city, by constructing coal futures trading, creating international coastal logistics base and upgrading port logistics function,

\section{E. Create High-tech Industries Demonstration Zone Focused by Digitization}

Relying on the advantage of natural harbor, Qinhuangdao should focuses on developing modern logistics transportation, high-end equipment manufacturing, modern information technology industry, and makes these industry formed a common development trend [6]. In the modern information technology industry, Qinhuangdao has to gradually strengthen marine finance and insurance services, marine information service industry, marine biological medicine and such marine emerging industries, foster a batch of Internationally renowned enterprises and brands and construct industry cluster with stronger international competitively.

\section{THE SUPPORTING MEASURES OF QINHUANGDAO MARINE ECONOMY DEVELOPMENT}

\section{A. Construct the Comprehensive Transportation System, and Promote the Service Industry Development}

Qinhuangdao speeds up to implement the plan of "move the west port to the east", perfects the construction of port, railway, highway and airport, striving to improve the road traffic network extending in all directions. Taking the opportunity of cooperation with Dalian Commodity Exchange, a commodity electronic trading platform will be established, as well as the third party electronic payment platform enterprise. Qinhuangdao take the advantage of spot goods and futures goods markets to construct coal futures trading and strengthen the coal industry. There will be a large warehouse logistics support system, bulk commodity exchange, port cargo distribution center.

\section{B. Upgrade Marine Traditional Advantage Industry and Cultivate Strategic Emerging Industry}

By 2020, some traditional industries like marine fishery, marine transportation, and coastal tourism will remain as the important pillar of marine economic development. On the basis of steady development of the traditional advantage industry, the emerging high-tech industry development will be developed priority and cultivated as the leading industry of the marine industry upgrading strategy. From the view of industry technology progress, industry associations, industry contribution, the industries of marine oil gas, marine biological medicine, marine chemical, marine renewable energy and marine monitoring services have characters of long industry chain, high correlation degree, strong radial force and powerful driving force. These should be treated strategic industries related to the future of marine economy and even the development of coastal areas in Hebei.

\section{Complete the Space Integration and Regional Layout Optimization of Marine and Ocean Side Industry}

Haigang district relies on Qinhuangdao port, mainly depends on the port logistics, land logistics and airport logistics, to perfect the port function, promote the harbour city interaction, create an International commodity distribution base of coastal port logistics. Shanhaiguan, Beidaihe, New Beidaihe districts focus on the modern tourism to develop of cultural creative industry of leisure tourism and seaside recuperate, promote coastal tourism extend from the coast to the sea. As the key district,New Beidaihe scientific layouts of major projects, carries out the major projects of tourism, animation creative accelerated, turns into a classic tourist area. Economictechnological Development Area of Qinhuangdao is based on port-vicinity industry clusters, mainly develop modern logistics, advanced equipment manufacturing, new energy, new materials and electronic information industries baked on the port and ship heavy industry to build a high-end manufacturing base. Coastal areas emphasis on aquaculture, recreational fishery, speeding up the development of shallow marine aquaculture and aquatic products processing industry. Shanhaiguan, Beidaihe, Funing, Changli carry out the development of marine aquaculture in large-scale, to build a national health ecological farming demonstration area, spread healthy 
ecological breeding pattern and carry out construction of sea ranch, gather the high value of fishery resources.

\section{Strengthen Protection and Restoration of the Coastline and Key Sea Area Resources and Environment}

The combination of marine economic growth mode transformation, marine industry and the spatial layout optimization of ocean industrial, will promote the synchronous development of marine economy and marine environmental protection, strengthen the infrastructure assurance of the sustainable development of marine economy's resources and environmental. By the year 2020, the major tasks are protection of sea coast, governance of marine ecological environment and the recovery of renewable ability of marine biological resources.

\section{REFERENCES}

[1] Du Liqiang, The protection and sustainable utilization of marine biological resources in Qinhuangdao. Journal of Anhui Agricultural Sciences, 40(22), pp. 11377-11379, 2012.

[2] The file assembly Qinhuangdao the Twelfth Five-Year Plan for national economic and social development (below). Development and Reform Commission of Qinhuangdao, pp. 464, 2012.

[3] Yan Yin, The situation analysis of Qinhuangdao fishery industry structure and development countermeasures. Hebei Fisheries, (4), pp. 50-52, 2009

[4] The development strategy of Qinhuangdao economic, technological and society in 2000 . The economic development and reform commission of Qinhuangdao, pp. 464, 2012.

[5] Wang Jianyou, Zhoushan marine development path of evolution, path dependence and strategic outlook. Ocean Development and Management, 27(5), pp. 99-104, 2010.

[6] Li Jun, A study of sea and land resources development strategy of Shandong peninsula blue economic zone. China population, resources and environment, 20(12), pp. 153-158, 2012.

[7] Han, Limin, The strategic thinking of Weifang blue economic zone construction. Journal of ocean university of china (Social Sceences Edition), (6), pp. 39-43, 2009. 